\title{
Research on the College Students' Employment Ability Development with Concept of Career Development
}

\author{
Zhang Rui \\ College of Computer Science, Neijiang Normal University Neijiang, Sichuan 641112 \\ ruizh-80@163.com
}

Keywords: Professional career; Employment; Ability training; Concept of career development

\begin{abstract}
It is the current issues of common concern that college students' employment problem in society. It's important to improve the employment rate and promote the development of social economy. How to improve college students' employment ability? Only develop their independent innovation ability and let them realize self-worth, can farther development his career. The author put forward its own views from the current employment situation with problems of current employment situation, which make the corresponding research based on the concept of career development.
\end{abstract}

\section{Introduction}

Since the early 21 st century, higher education of our country grows vigorously, the university graduates from 2000 in 3.01 million soared to 2010 in 6.3 million, and college students will soon become the main force of social development in the future. But there are still a lot of college students who are facing career development issues. They mainly embodied in applying for and choosing an appropriate job. During the period of school many students don't have a clear life planning. When interviewing, they have no accurate career orientation. Helping college students solve the problem of career and be prepared for the future development, which has become an important subject that current higher education are facing.

\section{The Necessity of Developing Career Ability}

It refers to a certain time of career mode, which individual through the work is purposive and has continuity of certain period of time. Since the career planning is to implement in the career, we are on track to analyze how to perfect the establishment of the planning. Establish a good professional view, can better help college students to discover their potential, better plan their career. [1]

We need cooperation with school, society and the individual which establish the right employment attitude, they must relook into problem from every possible angle, further providing better reference for today's college students.

University students' employment problem is the common concern problems in society. How to solve the current severe employment situation, improve the competitive advantage of the college students' employment, which are many scholars discussing and focusing.

The writer think that the development of the current college students' employability should be drawn from following aspects, colleges and enterprises should provide a new way for talents cultivation from the perspective of multidimensional.[2]

\section{Employment Problems}

The appropriate employed population in our country is very large, so employment contradiction is very outstanding, and the number of college graduate is rising year by year, whether their own or external factors will affect their employment at present. They are mainly incarnate in the following aspects: 
Attitude towards Employment. A person's attitude is the key to decide whether he can succeed. A one who have a positive and healthy attitude, when choosing a career, he is bound to be objective that can find his right direction. [3] On the contrary, negative attitude will seriously affect the direction of their own judgment, they could escape even small setbacks. College students' psychological quality is the internal factors that affect the employment, The right attitude can help them significantly improve their own capabilities.

Professional Knowledge. With the growing popularity of the higher education in China, the development of education improved a lot. The result also brought many problems, Such as students' basic knowledge is not solid, professional knowledge is not comprehensive, they can't combine knowledge with practice perfectly, it played a big role in our interview. Professional knowledge is the key to apply for success. Only firmly grasp knowledge and meet the needs of the enterprise, we can find a good job. [4]

Career Goals. Many students graduate in the near graduation even don't know what you should do. Not a clear career orientation and goals of employment lead to no direction in choosing a job. Contemporary college students need to have a clear career goal, select the right direction of alignment positioning in their life.

Employment Situation. Since 1999, continuously expanding enrollment in colleges and universities, the graduates will be high every year into jumped, appear the phenomenon of "supply". Around the severe employment situation, the "difficult employment "problem has become one of social hot issues.

\section{Situations for Employment Ability}

Set up Related Courses. To meet the demand of talents under the market economy, university education should be combined with social and economic development, set up related courses with employment as guide, strengthen the market research, according to the market demand in a timely manner to adjust and optimize the structure of professional, create better talent mechanism, meet the needs of the current situation, assist students to establish a complete career planning. [5]

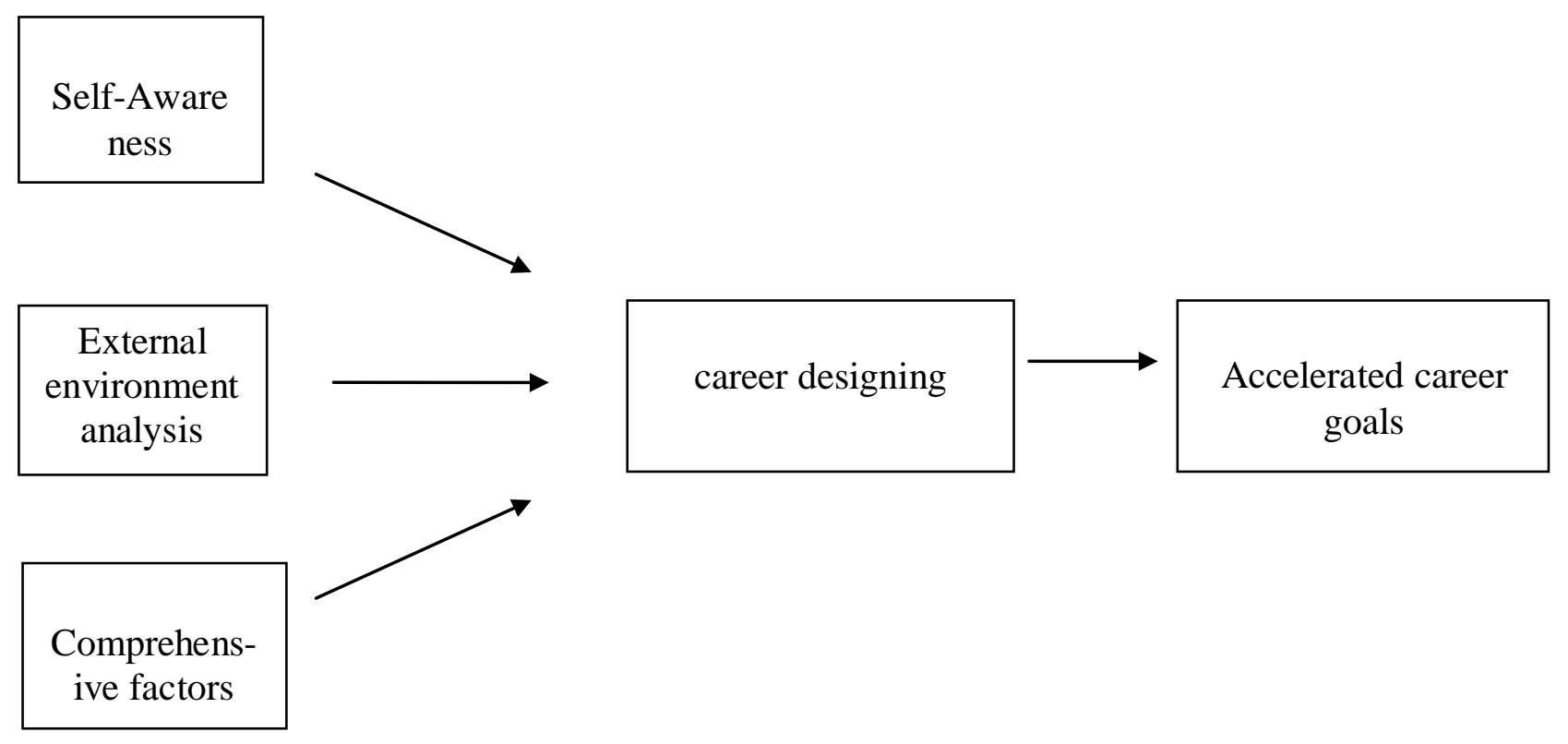

Figure 1. Career course analysis 
University-enterprise Cooperation. To improve the independent innovation ability of students in colleges and universities, the best thing to do is enhancing university-enterprise cooperation. [6] Colleges and universities according to the demand of choose and employ enterprise, set out relate courses, adjust training goal. Make enterprise staff participation, development and design courses, invite industry elite to topic seminar, create a better mode of talent training, for example, construct the scientific research bases, started speaking course, combining theory and practice. We can draw lessons from the British "sandwich course mode", (As shown in Fig. 2) make the students have the opportunity to practice and theory together, at the same time, through practice, students can understand their interests and ability, thus more clear their career direction.

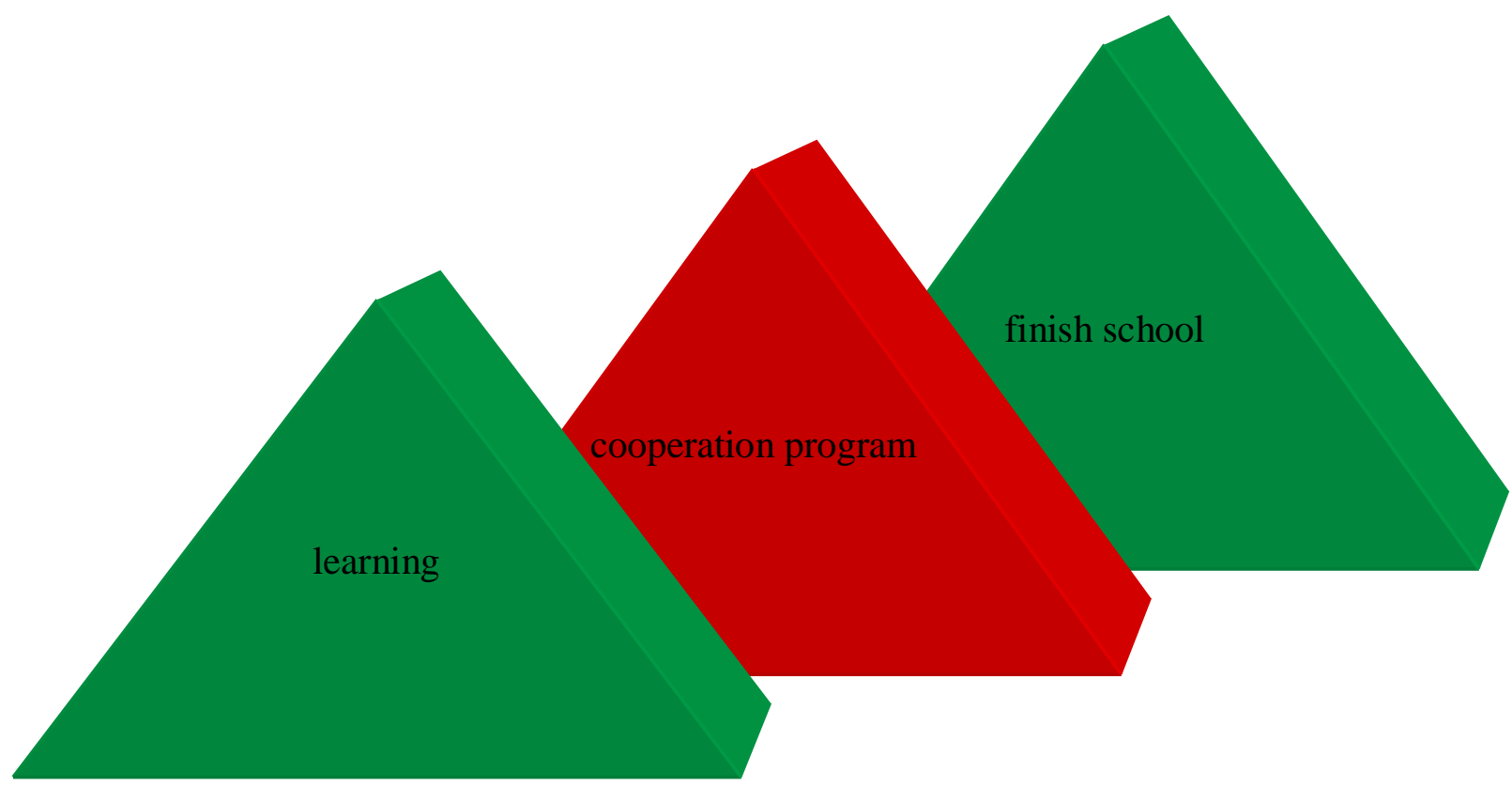

Figure. 2

Changing the Concept of Choosing a Career. Many college students choose to stay in big cities after graduation, and don't want to go to some small and medium-sized cities and even remote locations. This is understandable, of course, but in the face of the current severe employment situation, enterprise or business unit of choose and employ persons tension, not so plenty of job opportunities, this needs to explore new avenues of employment, changing the concept of choosing a career. [7] According to their own conditions and strength level, they can choose a few young start-ups, or to some small and medium-sized cities, it will have a bigger development space. [8]

Self-employment. Self-employment is the current hot topic, and the state for the college students' entrepreneurship support is also a favorable current trends. In recent years, our country also have many entrepreneurship policy for college students, providing a certain financial support, technical guidance and good business environment. The entrepreneurship of College students has the following advantages: 
1) Strong curiosity for new things and fashion trends

2) Get effective information witn Internet to help themslves

3) Breaks through the traditional thinking, the new ideas and understanding for starting a business

\section{Summary}

University students' employment is about to the healthy development of social economy. In order to cultivate high-quality talents, perfect our country's employment mechanism, improving our country's employment rate, colleges and universities, society and individuals should unite to strengthen the guidance role of college students. ${ }^{[9]}$ School and enterprise should through classroom education, cooperation between school and enterprise, and helping them establish a good professional view. Also College students should be fully develop themselves that recognize the current employment situation and adjust their own state of mind, so that they can actively respond to challenges, improve themselves, be prepared for employment, thus they can meet the social challenges with better attitude and contribute to the economic development of our country. [10]

\section{References}

[1] Wenzhun Huang, Xinxin Xie, Wei Bian, Hui Zhang. Research on the Competition Training Course System for College Students under the Employment and Ability Oriented Background [A]. Singapore Management and Sports Science Institute, Singapore. Proceedings of $2016 \mathrm{PPH}$ International Conference on Social Science and Environment(PPH-SSE 2016 V6)[C].Singapore Management and Sports Science Institute,Singapore:,2016:6.

[2] YI Zhong. The Research of Self-Cultivation of Employment Ability for College Students under the Background of Popular Education [A]. Intelligent Information Technology Application Association. Proceedings of the 2011 Fourth International Symposium on Knowledge Acquisition and Modeling (KAM 2011) [C].Intelligent Information Technology Application Association: 2011:4.

[3] Yongfang Liu. The Study on Education Reform for College Students Employment Competition Ability [A]. Intelligent Information Technology Application Association. Future Communication, Computing, Control and Management (ICF4C 2011 LNEE 142) [C].Intelligent Information Technology Application Association: 2011:6.

[4] Kai Zhou, Ying Zhao. Discussing the Duality of Ability Development of College Student Leaders [A]. Information Engineering Research Institute, USA. Proceedings of 2013 2nd International Conference on Social Science and Education(ICSSE 2013) Volume 47[C].Information Engineering Research Institute,USA:,2013:4.

[5] Bai Jing Agricultural University of Hebei Baoding Hebei China Zhang Guolin Agricultural University of Hebei Baoding Hebei China. Brief Discussion for University Students' Professional Career Guidance [A]. IEEE Beijing Section、Zhengzhou Institute of Aeronautical Industry Management. Proceedings of 2012 IEEE International Conference on Engineering Technology and Economic Management (ICETEM2012) [C].IEEE Beijing Section、Zhengzhou Institute of Aeronautical Industry Management: 2012:4.

[6] Zhang Sha, Shen Shi-yong. Research on the College Students' Self-management in the View of Professional Career-management [A]. University of Electronic Science and Technology of China、 The American Society for Public Administration、Chinese Public Administration Society、The School of Public Administration of Moscow State University、The Chinese Public Administration 
Journal. Proceedings of 2011 International Conference on Public Administration(7th)(Volume I )[C].University of Electronic Science and Technology of China、The American Society for Public Administration 、 Chinese Public Administration Society 、The School of Public Administration of Moscow State University、The Chinese Public Administration Journal: 2011:5.

[7] Gao Renfan. Combine Vocational Training and Employment Guidance Increase the Employment Rate of Civil Engineering Graduates [A]. Information Engineering Research Institute, USA. Proceedings of 2012 International Conference on Computer, Control, Education and Management (CCEM 2012)[C].Information Engineering Research Institute,USA:,2012:6.

[8] Lihua Zhao, Jixun Ma. Discussion on Professional Quality of Career Guidance Staff in Colleges and Universities [A]. Information Engineering Research Institute, USA. Proceedings of 2014 2nd International Conference on Social Science and Health (ICSSH 2014 V56) [C].Information Engineering Research Institute, USA: 2014:4.

[9] Qianyun Kong, Yu Zhao, Qingli Zhao. Construction of Local University Students' Entrepreneurship Education System [A]. Information Engineering Research Institute, USA. Proceedings of 2014 4th International Conference on Applied Social Science(ICASS 2014 V52)[C].Information Engineering Research Institute, USA:,2014:5.

[10] Guiping SHAO Zhejiang Vocational College of Commerce, Hangzhou, China. Study on the Entrepreneurship Education Strategic Plan at Higher Learning Schools under the Performance Excellence Model [A]. Scientific Research Publishing, Capital University of Economics and Business, China, Hohai University, China 、 Jiangxi University of Finance and Economics, China、 Shanghai Second Polytechnic University. Proceedings of the 2011 International Conference on Education Science and Management Engineering(part 2)[C].Scientific Research Publishing 、 Capital University of Economics and Business, China, Hohai University, China, Jiangxi University of Finance and Economics, China、Shanghai Second Polytechnic University: 2011:4. 